\title{
MANFAAT FORMULIR RESUME MEDIS BAGI PETUGAS BPJS DI RUMAH SAKIT IBU DAN ANAK ERIA BUNDA PEKANBARU
}

\author{
Doni Jepisah, Gussri Anggraini \\ Dosen dan Mahasiswa Prodi D3 Rekam Medik dan Informasi Kesehatan \\ STIKes Hang Tuah Pekanbaru \\ Email: dhonibhungsu@ymail.com dan Gussrianggraini@yahoo.com
}

\begin{abstract}
The production process design is the form one's creativity in the form of a paper form or electronic form in the form of visual communication which has the function and aesthetic value to convey information or a message to everyone who has arranged the format so as to comply with certain requirements. Electronic form is a space that is displayed on the computer screen that is used to capture the data to be processed in an electronic data processing. The method used is descriptive qualitative approach is also called non statistik data processing. Data analysis techniques used in this research is the technique of inductive thinking process; that is to say, in testing hypotheses starts from the data collected and summarized, this technique is usually used to analyze the data obtained from observation and interviews Results showed Desai electronic form in the hospital sassy yellow pekanbaru not run well, hospitals are still using manual design, while at the present time other hospitals already use electronic medical records to facilitate the work, reductions loss of data and a double storage. The conclusion from this study that the factors that make hospitals sassy yellow pekanbaru not use an electronic medical record that there is no concern for the hospital to work in the system of medical records.
\end{abstract}

Keywords: Resume Form Of Medical Benefits, Attendant at the Hospital BPJS.

\section{PENDAHULUAN}

Sistem Kesehatan Nasional (SKN) adalah bentuk dan cara menyelenggarakan pembangunan kesehatan yang memadukan berbagai upaya bangsa indonesia dalam satu derap langkah guna menjamin tercapainya tujuan pembangunan kesehatan dalam kerangka mewujudkan kesejahteraan rakyat sebagaimana dimaksud dalam Undang-Undang 1945. Pembangun kesehatan adalah upaya yang dilaksanakan oleh semua komponen bangsa yang bertujuan untuk meningkatkan kesadaran, kemauan, dan kemampuan hidup sehat bagi setiap orang agar peningkatan derajat kesehatan masyarakat yang setinggi-tingginya dapat terwujud (DepKes RI, 2009: 2).

Berbagai macam cara dan sistem yang digunakan untuk meningkatkan mutu pelayanan kesehatan. Salah satu jalan untuk menunjang peningkatan pelayanan kesehatan adalah adanya sistem rekam medis yang baik. Rekam medis merupakan keterangan baik tertulis maupun yang terekam tentang identitas, anamnesa, pemeriksaan fisik, laboratorium, diagnosa serta segala pelayanan dan tindakan medis yang di berikan kepada pasien, dan pengobatan baik rawat inap, rawat jalan maupun yang mendapatkan pelayanan gawat darurat (DepKes RI, 2006:11)

Ada beberapa kegunaan dari rekam medis antara lain menyangkut aspek dokumentasi dan keuangan. Suatu berkas rekam medis mempunyai nilai uang, karena isinya mengandung data dan informasi yang dapat dipergunakan sebagai aspek keuangan. Kaitan rekam medis dengan aspek keuangan sangat erat sekali dalam hal pengobatan, terapi serta tindakan-tindakan apa saja yang diberikan kepada seorang pasien selama menjalani perawatan di rumah sakit (DepKes RI, 2006:15).

Salah satu dari manfaat rekam medis adalah sebagai dasar didalam perhitungan biaya pembayaran pelayanan yang diterima oleh pasien. Terdapat beberapa cara pembayaran pelayanan kesehatan yang dilakukan oleh pasien yaitu bayar sendiri, asuransi kesehatan dan tanggungan perusahaan (Ilyas, 2003: 3).

Asuransi kesehatan merupakan salah satu produk asuransi yang mempunyai beberapa kategori. Pada dasarnya asuransi kesehatan memberikan manfaat tertentu apabila tertanggung mengalami sakit, kecelakaan atau 
menerima pelayanan medis. Kategori utama asuransi kesehatan adalah ketidak mampuan berpenghasilan, asuransi biaya medis tradisional dan Managed Care. Asuransi ketidak mampuan berpenghasilan memberikan jaminan pembayaran sebagai dari penghasilan tertanggung apabila tertanggung mengalami sakit atau kecelakaan sehingga tidak dapat bekerja. Asuransi biaya medis tradisional memberikan jaminan pembayaran biaya perawatan kesehatan apabila tertanggung mengalami sakit atau kecelakaan. Managed Care memberikan jaminan dengan mengintegrasikan antara pembiayaan dan pelayanan kesehatan. Hal ini dikarenakan sistem ASKES di Indonesia menggunakan sistem Managaed Care dimana pemegang polis tidak dipersyaratkan untuk melakukan pembayaran terlebih dahulu kepada rumah sakit (Thabrany, 2002:89).

Dalam pelayanan rumah sakit, sering terdapat Bad Debt, yang merupakan biaya rumah sakit yang tidak bisa ditagihkan kepada pasien atau keluarga pasien. Agar rumah sakit bisa terus menyediakan pelayanan, bersarnya Bed Dabt harus dikompesasikan dengan penerimaan lain, yang sering dibebankan, baik secara eksplisit maupun diperhitungkan dalam rencana perhitungan tarif kepada pasien lain yang mampu membayar atau yang dibayar oleh majikan atau oleh perusahaan asuransi (Hatta, 2008: 24).

Menurut UU RI No 2 Tahun 1992 tentang asuransi disebutkan bahwa program asuransi yang diselenggarakan secara wajib berdasarkan suatu undang-undang dengan tujuan untuk memberikan dasar bagi kesejahteraan masyarakat (Thabrany, 2002:9).

Maka pemerintah mengembangkan sistem asuransi kesehatan (ASKES) yaitu PT (Persero) Asuransi Kesehatan Indonesia, pengembangan tugas dari pemerintah untuk menyelenggarakan jaminan kesehatan bagi pegawai negri sipil (PNS), penerimaan pensiun, veteran, dan perintis kemerdekaan serta anggota keluarganya. Pegawai negri sipil atau penerimaan pensiunan wajib membayar iyuran setiap bulan yang berdasarkan serta tata cara pemungutannya ditetapkan dengan keputusan presiden (Thabrany, 2002:38).

Upaya pemerintah dalam mempercpat terselenggaranya sistem jaminan nasional secara menyeluruh bagi rakyat indonesia maka dibentuklah suatu Badan Penyelenggara Jaminan Sosial (BPJS) dengan Undang-Undang RI No 24 Tahun 2011. Dimana BPJS merupakan transformasi dari empat badan usaha milik negara (BUMN) yaitu PT. Askes, Jamsostek, Taspen dan Asabri

Badan Penyelenggara jaminan sosial (BPJS) adalah badan hukum publik yang dibentuk untuk menyelenggarakan program jaminan sosial. BPJS terdiri dari BPJS Kesehatan dan BPJS Ketenagakerjaan. Badan Penyelenggara Jaminan Sosial (BPJS) Kesehatan mulai pada tanggal 1 Januari 2014.

Peserta BPJS Kesehatan ada 2 kelompok, yaitu PBI jaminan kesehatan dan Bukan PBI jaminan kesehatan. PBI (Penerima Bantu Iuran) adalah peserta Jaminan Kesehatan bagi fakir miskin dan orang tidak mampu sebagaimana diamanatkan UU SJSN yang iurannya dibayari pemerintah sebagai peserta program Jaminan Kesehatan. Yang berhak menjadi peserta PBI Jaminan Kesehatan lainnya adalah yang mengalami cacat total dan tidak mampu.

Menurut PP Nomor 46 Tahun 2014 tentang sistem informasi kesehatan dikelola secara berjenjang, terkoneksi, dan terintegrasi serta didukung dengan kegiatan pemantauan, pengendalian, dan evaluasi. Pengelolaan sistem informasi kesehatan nasional didasarkan pada standar data kesehatan, informasi kesehatan, dan indikator kesehatan untuk menghasilkan data dan informasi yang di butuhkan.

Satu di antara sistem pengolahan data yang penting dalam sistem Rekam Medis adalah sistem pengkodean. Pemberian kode merupakan suatu penetapan kode dengan mengkombinasikan huruf atau angka atau kombinasi huruf dalam angka yang mewakili komponen data. Pemberian kode bertujuan untuk menyeragamkan nama dan golongan penyakit cedera, gejala dan faktor yang mempengaruhi kesehatan. Kecepatan dan ketepatan pemberian kode dari satu diagnosis 
sangat tergantung kepada pelaksana yang menangani berkas rekam medis tersebut yaitu tenaga medis dalam menetapkan diagnosa, tenaga rekam medis sebagai pemberi kode, serta tenaga kesehatan lainnya. Karena ketepatan diagnosa sangat mempengaruhi dalam pembuatan indeks, pelaporan dan sistem pembiayaan.

Menurut Departeman Kesehatan RI Tahun (2006) kecepatan dan ketepatan koding dari satu diagnosa sangat tergantung kepada pelaksanaan yang menangani rekam medis tersebut adalah: tenaga medis dalam menetapkan diagnosa, tenaga rekam medis sebagai pemberi kode, dokter yang mengisi formulir rekam medis dan tenaga kesehatan lainya dalam melengkapi formulir rekam medis.

Rumah Sakit Ibu dan Anak merupakan salah satu rumah sakit rujukan untuk pasien ASKES dimana pasien memperoleh pelayanan kesehatan tanpa bergantung pada terjadinya uang tunai baik pelayanan rawat jalan maupun rawat inap. Setelah masa perawatan di rumah sakit selesai dan tertanggung diperbolehkan pulang, tertanggung dapat langsung meninggalkan rumah sakit tanpa melakukan pembayaran. Semua biaya perawatan selama tertanggung dirawat dirumah sakit kemudian akan ditagih oleh pihak rumah sakit kepada perusahaan asuransi (ASKES). Adapun syarat untuk pengklaimannya adalah harus ada data medis tertanggung yang telah diisi dokter dengan lengkap dan benar. Berdasarkan observasi awal penulis di Rumah Sakit Ibu dan Anak Eria Bunda, khusus manfaat berkas rekam medis rawat inap bagi ASKES adalah dimana kelengkapan berkas rekam medis tersebut sangat berpengaruh untuk kelancaran proses pengklaiman dari pihak rumah sakit ke pihak asuransi. Namun di dalam pengisian Formulir Resume Medis masih banyak di temui tidak diisi lengkap oleh Petugas Rekam Medis dan Dokter. Yang sering tidak diisi lengkap adalah seperti identitas pasien yang tidak diisi sebanyak 22 (5\%) dan tanda tanggan Dokter yang tidak diisi sebanyak 22 (5\%). Berdasarkan UU Kedokteran No 46 pasal 2 menyebutkan bahwa rekam medis harus dilengkapi setelah pasien selesai menerima pelayanan kesehatan. Dengan pentingnya kelengkapan pengisian berkas rekam medis rawat inap.Kelengkapan formulir rekam medis sangat penting peranannya dalam administrasi dan keuangan seperti yang diketahui pembiayaan BPJS bergantung dengan kode yang diberi oleh petugas rekam medis berdasarkan lembar resume medis yang diisi oleh dokter, dengan lengkapnya resume medis dapat bermanfaat bagi pengobatan pasien selanjutnya.Oleh karena itu kelengkapan formulir resume medis berpengaruh dan bermanfaat bagi BPJS khususnya dalam hal administrasi dan keuangan.

\section{METODOLOGI PENELITIAN}

Penelitian ini adalah penelitian deskriftif kualitatif untuk memperoleh informasi dan gambaran yang jelas tentang manfaat formulir resume medis pasien rawat inap bagi petugas BPJS di Rumah Sakit Ibu dan Anak Eria Bunda Pekanbaru

Subjek dalam penelitian ini terdiri dari dua orang yaitu petugas rekam medis bagian pengolahan data dan petugas BPJS di Rumah Sakit Ibu dan Anak Eria Bunda Pekanbaru seperti pata tabel berikut:

Tabel 1 Jumlah Informan Penelitian

\begin{tabular}{llll}
\hline No & \multicolumn{1}{c}{ Jabatan } & Pendidikan & $\begin{array}{c}\text { Lama } \\
\text { Bekerja }\end{array}$ \\
\hline 1 & Staf & D III & 1 Tahun \\
2 & Pengolahan & D III & 1 Tahun \\
& Data & & \\
& Petugas BPJS & & \\
\hline
\end{tabular}

Sumber: RSIA Eria Bunda Pekanbaru

3. HASIL DAN PEMBAHASAN

A. Manfaat Resume Medis Sebagai Aspek Administrasi Bagi Petugas BPJS Di Rumah Sakit Ibu Dan Anak Eria Bunda Pekanbaru

a. Observasi

Berdasarkan hasil observasi diperoleh data bahwa jumlah pasien rawat inap yang menggunakan BPJS di Rumah Sakit Ibu dan Anak Eria Bunda Pekanbaru pada bulan Mei 2015 berjumlah 468 pasien. Dari 468 pasien terdapat 98 pengisian formulir resume medis 
yang tidak lengkap. Hal ini menunjukkan bahwa fungsi administrasi masih kurang optimal.

Tabel 2. Lembaran check list ketidak lengkapan Klaim BPJS

\begin{tabular}{llcr}
\hline No & Keterangan & Ada & Tidak \\
\hline 1 & Ktp & $\checkmark$ & \\
2 & Kartu Bpjs Asli & $\checkmark$ & \\
3 & Rincian Biaya & $\checkmark$ & \\
4 & Copy Hasil & $\checkmark$ & \\
5 & Penunjang & & $\checkmark$ \\
6 & Resume Medis & $\checkmark$ & \\
& Surat Jaminan & & \\
\hline
\end{tabular}

RSIA Eria Bunda Pekanbaru

Dari hasil tabel 2 diatas menunjukkan bahwa syarat pengajuan klaim yang sudah ada yaitu kartu KTP sudah lengkap, kartu BPJS sudah lengkap, rincian biaya, copy hasil penunjang serta surat jaminan sudah lengkap, sementara untuk resume medis belum ada. Untuk pengklaiman asuransi semua persyaratan diatas harus ada dan diisi lengkap supaya bisa digunakan.

\section{b. Wawancara}

Dari hasil wawancara diketahui bahwa rekam medis sangat bermanfaat bagi aspek administrasi karena isinya mengandung semua data tentang pasien. Jika tidak ada rekam medis maka pelayanan tidak bisa berjalan dengan secara optimal. Seperti pernyataan berikut:

"Rekam Medis sangat penting, karena tanpa adanya rekam medis maka pelayanan tidak bisa berjalan dengan optimal, karena semua data pasien ada di rekam medis, mulai dari pasien masuk sampai pasien pulang."

Hasil wawancara dengan petugas BPJS tentang syarat-syarat pengajuan BPJS, hambatan apa yang sering terjadi serta apa untuk mempelancar proses pengklaiman, Seperti pernyataan berikut:

"Sebelum pasien dilayani, pasien harus melengkapi persyaratan administrasi karena kalau tidak lengkap peserta tidak bisa dijamin dalam pembayaran BPJS tersebut."
"Untuk syarat-syaratnya biasanya harus ada KTP, kartu BPJS asli, rincian biaya, copy hasil penunjang, resume medis, surat jaminan".

"Hambatan atau masalah yang sering terjadi biasanya pada resume medis, karena ada resume medis yang pengisiannya tidak lengkap, itu sangat menghambat proses klaim, karena pihak asuransi tidak bisa menerima jika resume medisnya tidak diisi lengkap".

Dari wawancara diatas dapat diketahui bahwa syarat pengajuan klaim BPJS yaitu KTP, kartu BPJS, rincian biaya, copy hasil penunjang, resume medis, surat jaminan. Hambatan yang sering terjadi yaitu ketidak lengkapan dalam pengisian resume medis pasien.

\section{B. Manfaat Resume Medis Sebagai Aspek Keuangan Bagi Petugas BPJS Di Rumah Sakit Ibu Dan Anak Eria Bunda Pekanbaru Tahun 2015}

a. Observasi

Berdasarkan hasil observasi diperoleh data bahwa jumlah pasien rawat inap yang menggunakan BPJS di Rumah Sakit Ibu dan Anak Eria Bunda Pekanbaru pada bulan juni 2015 berjumlah 468 pasien. Dari 468 pasien terdapat 98 pengisian formulir resume medis yang tidak lengkap. Karena sebanyak 98 pasien yang berobat ke Rumah Sakit Ibu dan Anak Eria Bunda Pekanbaru pada bulan april pembayarannya tertunda yang disebabkan karena tidak lengkapnya syarat pengklaiman ke pihak BPJS yaitu dalam pengisian resume medis. Hal ini sangat berpengaruh pada aspek keuangan rumah sakit.

b. Wawancara

Hasil wawancara tentang manfaat keuangan bagi petugas BPJS di Rumah Sakit Ibu dan Anak Eria Bunda Pekanbaru yaitu diperoleh informasi bahwa rekam medis sangat berpengaruh sebagai aspek keuangan karena isi rekam medis dapat dijadikan sebagai bahan untuk menetapkan biaya pembayaran pelayanan di rumah sakit. Tanpa adanya bukti catatan tindakan atau pelayanan maka pembayaran tidak dapat dipertanggung jawabkan, seperti pernyataan berikut: 
"manfaat dari segi keuangan adalah isi rekam medis dapat dijadikan sebagai bahan pembayaran pelayanan, karena didalam formulir resume medis ada diagnosa, tindakan dan obat-obatan yang telah diberikan kepada pasien. Jika tidak ada diagnosa medis maka pembayaran tidak bisa ditagihkan baik kepada pasien maupun kepada pihak lain yang menjadi penanggung jawab pasien."

"Dari segi keuangan, rekam medis sangat penting karena untuk BPJS pembayarannya berdasarkan diagnosa medis pasien, diagnosa pasien rawat inap biasanya terdapat di formulir resume medis pasien, jika diagnosanya tidak ada maka proses pengklaiman akan terlambat.".

\section{KESIMPULAN DAN SARAN}

Kesimpulan

Dari hasil penelitian di Rumah Sakit Ibu Dan Anak Eria Bunda Pekanbaru penulis menarik kesimpulan sebagai berikut:

1. Manfaat formulir resume mdis sebagai aspek administrasi bagi petugas untuk kelengkapan persyaratan klaim BPJS di Rumah Sakit Ibu dan Anak Eria Bunda Pekanbaru belum berjalan secara optimal, dimana masih terdapat ketidak lengkapan dalam pengisian formulir resume medis yang mengakibatkan terkendalanya proses pengklaiman ke pihak BPJS.

2. Formulir resume medis sangat penting sebagai aspek keuangan karena untuk BPJS pembayarannya berdasarkan diagnosa medis pasien. Diagnosa pasien rawat inap biasanya terdapat di formulir resume medis pasien, jika diagnosanya tidak ada maka proses pengklaiman akan terlambat, sehingga berpengaruh terhadap keuangan rumah sakit.

\section{Saran}

Berdasarkan penelitian di Rumah Sakit Ibu Dan Anak Eria Bunda Pekanbaru memberi saran yaitu:

1. Diharapkan kepada petugas rekam medis, perawat dan dokter yang bersangkutan agar lebih memperhatikan lagi dalam pengisian formulir resume medis pasien terutama untuk pasien BPJS supaya pengklaiman ke pihak BPJS berjalan dengan lancar tanpa ada hambatan apa pun.

2. Diharapkan ada kebijakan dari pihak rumah sakit untuk pengisian formulir resume medis pasien BPJS supaya proses pengklaiman bisa berjalan dengan lancar sehingga tidak merugikan rumah sakit terutama pada aspek keuangan.

\section{DAFTAR PUSTAKA}

Darmawi, Herman. (2006). Manajemen Asuransi. Jakarta: Bumi Aksara

DepKes R.I (2006). Pedoman Penyelenggaraan dan Prosedur Rekam Medis Rumah Sakit di Indonesia. Jakarta: Depertemen Kesehatan Republik Indonesia

Nasional.
Nistem Kesehatan Jakarta

Hatta, Gemalan (2008). Pedoman Manajemen Informasi Kesehatan di Sarana Pelayanan Kesehatan. Universitas Indonesia

Herlambang, Susatyo (2012). Manajemen Kesehatan dan Rumah Sakit. Yogyakarta: Gosyen Publishing

Ilyas, Y. (2003). Asuransi Kesehatan. Depok: Fakultas Kesehatan Masyarakat Universitas Indonesia

Notoadmojo. S. (2005). Metode Penelitian Kesehatan. Jakarta: PT. Rineka Cipta -(2010). Metode Penelitian Kesehatan. Jakarta: PT. Rineka Cipta

Rustiyanto, E. (2009). Etika Profesi Perekam Medis \& Informatika Kesehatan. Yogyakarta: Graya Ilmu

Thabrany, Hasbullah. (2002). Asuransi Kesehatan di Indonesia. Depok: Pusat Kajian Ekonomi Kesehatan UI

Saryono. (2010). Metode Penelitian Kesehatan. Jogjakarta: Mitra Cendikia

Undang-Undang Republik Indonesia Nomor 44 Tahun 2009 Tentang Rumah Sakit. (2009). Bandung: Citra Umbara. 